J. Lake Sci.(湖泊科学), 2020, 32(4) : 899-914

DOI 10. 18307/2020. 0401

(C) 2020 by Journal of Lake Sciences

\title{
我们能拯救长江中正在消逝的鲟鱼吗?”
}

\author{
谢 平 $1,2 * *$ \\ (1: 中国科学院水生生物研究所东湖湖泊生态系统试验站, 武汉 430072) \\ ( 2 : 云南大学生态与环境学院高原湖泊生态与治理研究院, 昆明 650500)
}

\begin{abstract}
摘 要: 鲟鱼在地球上已生存了数亿年,体型变化小, 有 “活化石”之称, 是鱼类中最濒危的类群之一. 长江分布有 3 种鲟 鱼:白鲟(Psephurus gladius)、中华鲟(Acipenser sinensis)和达氏鲟(Acipenser dabryanus). 白鲟已经功能性灭绝, 中华鲟的灭 绝也难以阻挡, 而达氏鲟也处于极危的状态. 干流大坝的建设对繁殖行为的影响是最大的原因, 虽然酷鱼滥捕也起到了 推波助澜的作用. 之前主流专家关于大坝建设对鲟鱼的影响出现了严重误判, 大坝建成后实施的救鱼措施也收效甚微, 因为白鲟早已不见踪影, 中华鲟的野生种群也已经到了绝灭的边缘. 近年来流行水库温水下泄使中华鲟产卵推迟并导致 其无法产卵的观点, 但推迟并不能推论到无法产卵的结论, 因此依此所建议的水库联合调度即便能够实施也未必能够奏 效. 中华鲟体型巨大, 生命周期长, 生态可塑性小, 完成生活史需要跨越近海和长江的巨大空间, 对产卵的条件要求苛刻, 因此, 如它无法自然产卵, 灭绝就是迟早的事情. 在过去的近 40 年, 虽然人工放流了数百万尾中华鲟, 但成效不容乐观, 对 野生种群的补充微乎其微. 因此, 对鲟鱼濒危机制 (特别是自然繁殖条件的丧失) 以及人工放流效果的重新评估以及对救 鱼对策的重新调整已刻不容缓.
\end{abstract}

关键词: 白鲟; 中华鲟; 长江;功能性灭绝;人工放流;救鱼策略

\section{Can we save the disappearing sturgeons in the Yangtze River?*}

\author{
XIE Ping ${ }^{1,2 * *}$ \\ (1: Donghu Experimental Station of Lake Ecosystems, Institute of Hydrobiology, Chinese Academy of Sciences, Wuhan \\ 430072 , P.R.China) \\ (2: Institute for Ecological Research and Pollution Control of Plateau Lakes, School of Ecology and Environmental Science, \\ Yunnan University, Kunming 650500, P.R.China)
}

\begin{abstract}
Sturgeons have lived on the earth for hundreds of millions of years with little morphological changes, thus called as "living fossils". They are one of the most endangered fish groups. Among the three sturgeon species in the Yangtze River, Psephurus gladius has extincted functionally, Acipenser sinensis is going to become extinct in natural environments, and Acipenser dabryanus is also critically endangered. The negative effects of spawning behaviors caused by the construction of dams in the main river is the biggest reason, followed by overfishing. There are serious misjudgments in authoritative experts about the impacts of dam construction on sturgeons, and the measures taken to save the fish after the completion of the dam have little effect, as the paddlefish has long gone, and the wild population of Chinese sturgeon is on the verge of extinction. In recent years, there is a popular viewpoint that the release of warm water from the reservoir delayed the spawning of Chinese sturgeon, consequently with their failure to lay any egg. However, postponement doesn't lead to the conclusion that it's impossible to lay eggs. Accordingly, the proposed joint reservoir operation is not effective even if it can be implemented. As the giant and long-lived Chinese sturgeons have low ecological resilience, and need to cross a vast space between coastal waters and the upper Yangtze River to complete the life story, if they can't lay eggs naturally, their extinction will happen sooner or later. During the past decades, millions of Chinese sturgeons were released artificially into the Yangtze River, but few survived with little supplement to the wild population. Therefore, it is urgent to re-evaluate the endangered mechanisms (especially the ruined conditions for natural reproduction) and the effects of artificial release and to
\end{abstract}

* 2020-02-11 收稿; 2020-02-14 收修改稿.

中国科学院战略先导科技专项 (B 类) (XDB31000000) 资助.

** 通信作者;E-mail:xieping@ihb.ac.cn. 
re-adjust fish rescue strategies.

Keywords: Chinese paddlefishes; Chinese sturgeons; Yangtze River; functional extinction; artificial release; fish rescue strategies

很多物理现象往往具有惊人的可预测性, 如遥远星辰的摇晃和转动, 这是一种美好而严格的科学. 但我 们对生态学趋势的预测就没那么精准了, 把握成千上万的物种交织在一起的现在就已经十分吃力了. 但种 间关系的复杂与变异并不意味着物种不存在稳定的生理节律. 事实上,有些物种对生存环境精准性的生理 追求十分悲催, 不惜自我毁灭, 不知是一种笨拙还是一种忠贞? 长江中的鲟鱼就是这样一个悲壮的类群. 复 杂性造就了精致性,而精致性却牺牲了可塑性.

鲟形目 (Acipenseriformes) 是软骨鱼类与硬骨鱼类之间的过渡类群, 是鱼类中最濒危的类群, $63 \%$ 的种类 处于极危 (critically endangered) 状态, 另外有 3 个种可能已经绝灭, 其余的 $30 \%$ 也受到威胁或处于易危或濒 危状态 ${ }^{[1]}$. 鲟鱼种群数量的下降源自过度捕捞、河流建坝和水污染等 ${ }^{[2]}$.

\section{1 古老的大型鱼类一一鲟鱼}

鲟形目包括鲟科 (Acipenseridae, 通俗英文名 Sturgeon)、匙吻鲟科 ( Polyodontidae, 通俗英文名 paddlefishes) 和一些灭绝的科. 鲟鱼是一种古老的鱼类一一我国曾在距今 2.5 亿多年前的二叠纪地层 (甘肃 省肃北县) 中发现过鲟形目鱼类化石, 称之为中华原始软骨硬鳞鱼 (图 1), 它兼有鲟形目鱼类、比耶鱼类和 古鳕类的一些特征, 可能是繁盛于古生代的古鳕类与自中生代开始繁荣的鲟形目鱼类之间的一个过渡 类群 ${ }^{[3]}$.
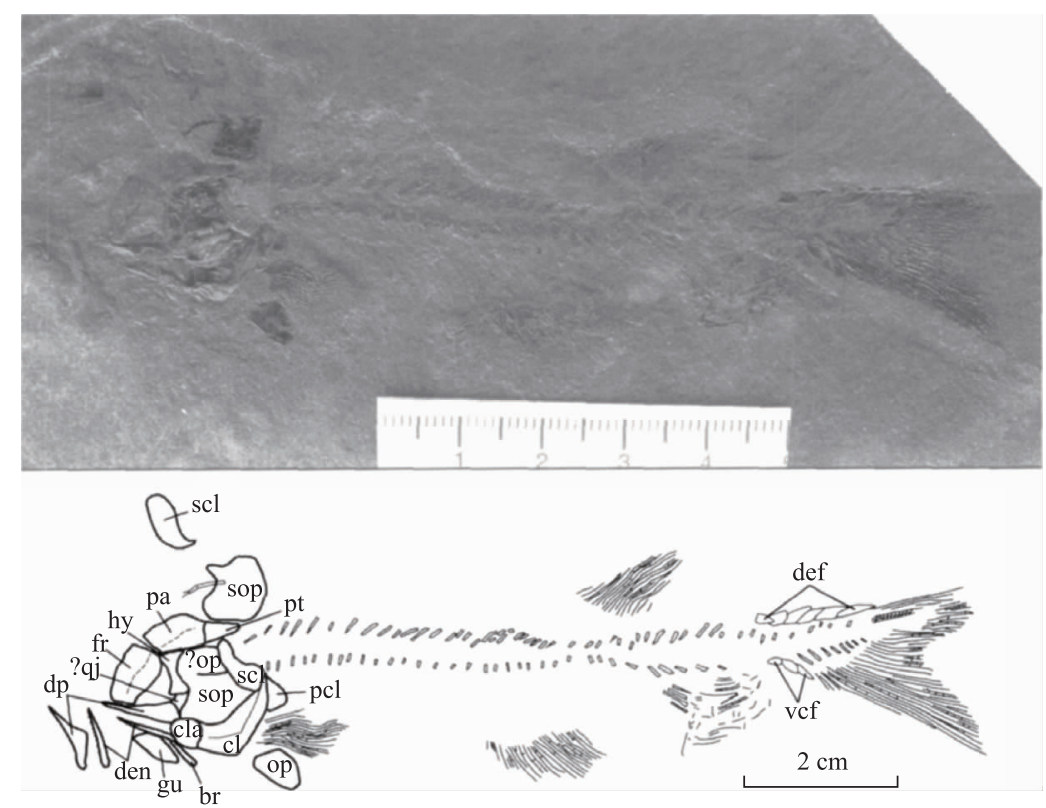

图 1 中华原始软骨硬鳞鱼 (新属、新种) 的正型标本及其骨骼轮廓 ${ }^{[3]}$

Fig.1 Eochondrosteus sinensis gen. et sp. nov., holotype and its skeletal outline ${ }^{[3]}$

在我国中生代地层发现过不少鲟形目鱼类化石, 如北票鲟、燕鲟、原白鲟、辽鲟等 ${ }^{[4]}$. 譬如, 在我国的一 些晚侏罗世地层中, 发现有辽宁北票的北票鲟(Peipiaosteus) (图 2) ${ }^{[5]}$, 河北丰宁的丰宁北票鲟 (P. fenningensis $)^{[6]}$, 辽宁凌源的刘氏原白鲟( Protopsephurus liui $)^{[3]}$.

鲟形目鱼类之所以被认为是原始鱼类, 是因为它们的形态特征与其最早的化石记录相比并无太大改 变, 因此也有 “活化石”之称 ${ }^{[7-8]}$. 全世界的鲟科 (Acipenseridae) 鱼类共有 27 种, 分为 4 个属一一鲟属 ( Aci- 


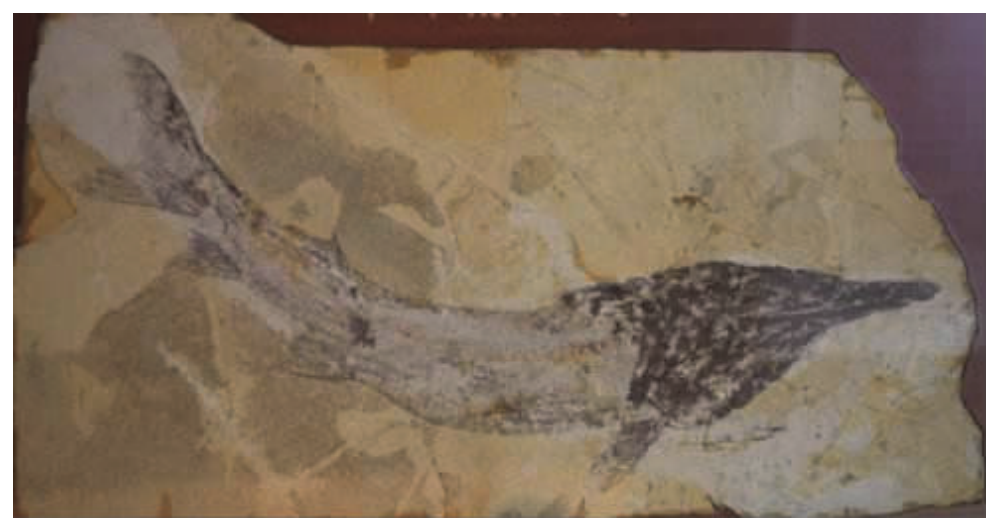

图 2 晚侏罗纪地层中的北票鲟 ${ }^{[5]}$

Fig. 2 Peipiaosteus from Beipiao of Liaoning ${ }^{[5]}$

penser)、鳇属 (Huso)、铲鲟属 (Scaphirhynchus) 和拟铲鲟属 (Pseudoscaphirhynchus). 全世界的匙吻鲟科鱼类更 少, 仅有两属两种: 一种是分布于长江的白鲟 (Psephurus gladius), 另一种是分布于密西西比河的匙吻鲟 (Polyodon spathula). 早在 20 世纪初, Sowerby ${ }^{[9]}$ 就曾这样描述道: “扬子江白鲟是所有中国令人印象深刻的 鱼类中的首位了. 扬子江白鲟属于匙吻鲟科鱼类, 在世界上仅存 2 属 2 种, 一种是中国的白鲟, 另一种即是 分布于北美密西西比河的匙吻鲟,两者皆属于鲟鱼类”.

根据线粒体基因组进行分子钟估算的结果, 鲟形目约起源于 3.62 亿 4.14 亿年前, 鲟和匙吻鲟大约是 在1.32 亿 1.60 亿年前分开的 ${ }^{[10]}$. 通过线粒体细胞色素 $\mathrm{b}$ 基因分子钟的估算,鲟和匙吻鲟的分歧约发生在 1.84 亿年前, 太平洋支和大西洋支的分歧时间约在 1.21 亿年前, 黑龙江一松花江一乌苏里江流域的史氏鲟与 长江流域的中华鲟和达氏鲟的分歧约发生于 0.70 亿年前, 而中华鲟和达氏鲟的分歧时间约在 1050 万年前, 密西西比河的匙吻鲟和长江的白鲟的分歧时间约在 0.68 亿年前(图 3 ).

鲟鱼是典型的冷水性鱼类, 寿命长, 性成熟晚, 体型大 ${ }^{[11]}$. 譬如, 欧洲鲟 (Huso huso) 可活 118 年, 1827 年 曾经在伏尔加河河口捕获的一条雌鱼体重达到 $1571 \mathrm{~kg}$ ! 四川省的渔浐中有 “千斤腊子万斤象” 的说法, 所 谓“腊子”是指中华鲟, “象”则是指白鲍 ${ }^{[12]}$.

许多鲟鱼属于溯河产卵的底栖鱼类,在生殖季节需到河流的上游去产卵,但大部分时间在河流三角洲 和河口地区摄食生长. 有些鲟鱼完全生活在淡水环境, 而有些则主要栖息于沿海水域之中, 虽然偶尔也能冒 险进入深海.

鲟形目鱼类广泛分布于北美与欧亚大陆,通过分子系统树可分为两支一一大西洋支和太平洋支 (图 4). 我国境内分布的野生鲟类有 8 种, 分布于黑龙江、松花江、乌苏里江流域的史氏鲟 (Acipenser schrenckii)、达氏 鳇(Huso dauricus) 和库页岛鲟( Acipenser medirostris), 分布于长江流域的中华鲟 (Acipenser sinensis)、达氏鲟 (Acipenser dabryanus) 和白鲟 (Psephurus gladius), 分布于新疆伊宁等地水域中的裸腹鲟 (Acipenser nudiventris), 以及分布于新疆额尔齐斯河、布伦托海、博斯腾湖的西伯利亚鲟 (Acipenser baeri). 栖息于长江之 中的中华鲟、达氏鲟和白鲟都已处于濒危状态,被列为国家 I 级保护野生动物.

\section{2 中华鲟一一正在走向灭绝}

中华鲟 (图 5) 是一种海河洄游性鱼类, 隶属于鲟形目鲟科鲟属. 中华鲟曾经分布于韩国西南部水域, 日 本九州西部水域, 中国的黄河、长江、珠江、闽江、钱塘江等水域. 但现在除了葛洲坝下的长江中下游之外, 中 华鲟在其他河流都已绝迹.

\section{1 生活简史}

中华鲟在长江上游出生, 在大海中成长, 最大个体曾有 $680 \mathrm{~kg}$ 的纪录, 寿命可达 40 龄. 中华鲟平时生活 在黄海、东海、南海北部的浅海区域, 以底栖动物 (虾、蟹、软体动物、头足类、水生昆虫和小杂鱼等) 为食, 雄 


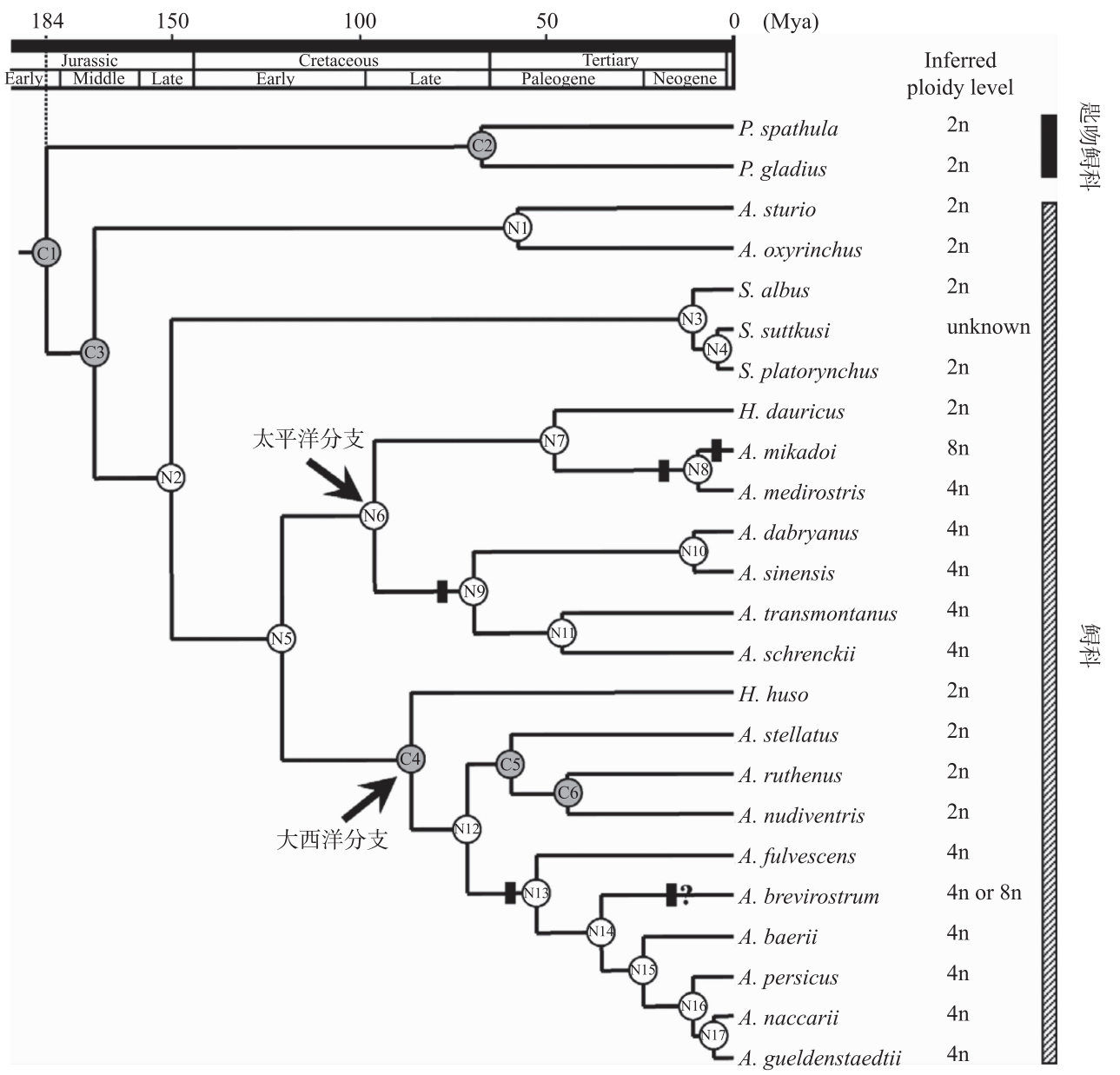

图 3 根据线粒体细胞色素 $\mathrm{b}$ 构建的有根的内类群数( 分支表示估算的分歧时间, C1 C6 表示校验节点,

$\mathrm{N} 1 \sim \mathrm{N} 17$ 为感兴趣的时间节点, 虚线表示鲟和匙吻鲟分歧时间 (百万年) 的后验平均值 ${ }^{[10]}$ )

Fig.3 Rooted ingroup tree based on cytochrome $\mathrm{b}$ gene sequences (Branches are shown to reflect divergence times estimated. C1-C6 are calibration nodes, N1-N17 are interest time nodes. A dash-dotted line indicates the posterior mean for divergence time in millions of years for split the sturgeons and paddlefishes ${ }^{[10]}$ )

鱼最早 8 龄、雌鱼最早 14 龄才达初次性成熟 ${ }^{[15-16]}$. 成熟个体需溯河洄游 $2500 \mathrm{~km}$ 以上以抵达长江上游的金 沙江 (宜宾一屏山) 河段方才进行产卵繁殖 ${ }^{[17]}$, 那里水流湍急, 底为砾石. 受精卵粘附于江底的岩石或石砾表 面进行䁔化.

中华鲟在秋季产卵. 亲鱼进人长江后要停留 1 年多时间,在此期间基本不摄食, 依靠体内积累的脂肪提 供繁殖过程中的能量消耗和性腺发育所需的物质, 待性腺由 III 期发育到 IV 期后, 于翌年秋季 10 月中旬一 11 月中旬产卵, 产后亲鱼迅速离开产卵场, 降河人海肥育 ${ }^{[18]}$ (图 6). 因此, 在长江中个体愈成熟, 身体愈消瘦. 幼鱼长大到 $15 \mathrm{~cm}$ 左右进人大海. 中华鲟在生殖洄游过程不进食而全靠消耗身体内的营养储备, 其忍耐饥 饿的能力是惊人的, 在硬骨鱼类中亦极为罕见. 中华鲟并非每年产卵, 根据对胸鯺第一鯺条磨片上的生殖标 志的观察推测 ,中华鲟重复产卵的间隔期至少为 $5 \sim 7$ 年 ${ }^{[15]}$.

中华鲟产卵后, 会有各种鱼类——圆口铜鱼 (Coreius guichenoti)、瓦氏黄滪鱼 (Pelteobagrus vachelli) 和铜 鱼 (Coreius heterodon) 等 10 多种底层鱼类——聚集在其播卵区, 吞食黏附在河流底质上的受精卵 ${ }^{[20]}$. 因此, 解剖食卵鱼也是监测中华鲟自然繁殖的传统方法 (图 7). 


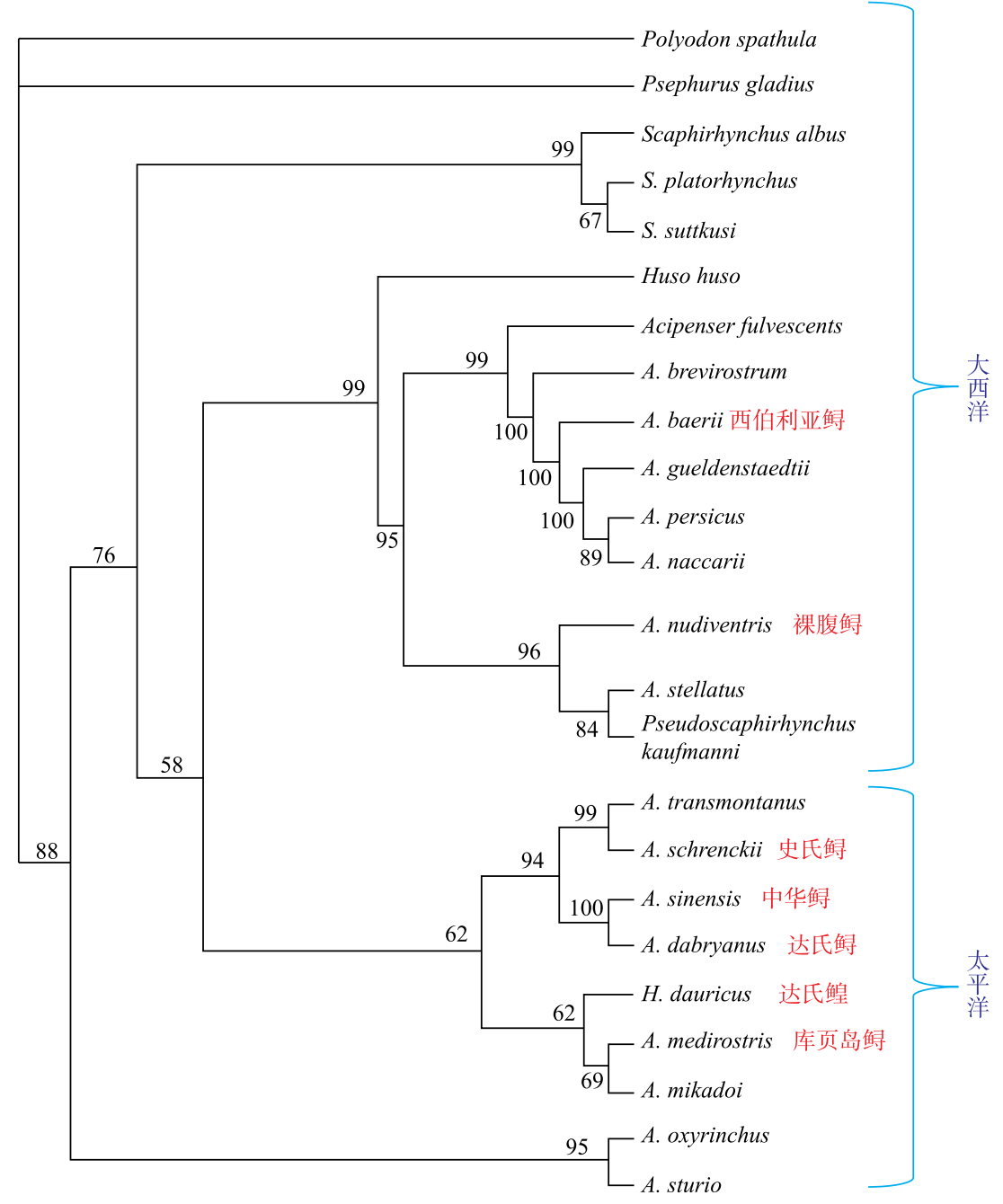

图 4 根据线粒体细胞色素 $\mathrm{b} 、 12 \mathrm{~S}$ rRNA、细胞色素 $\mathrm{c}$ 氧化酶亚基 II 、tRNA Phe、tRNA Asp、16S rRNA、

NADH5 和控制区基因序列 ( 8 个基因,4406 个位点)构建的鲟形目鱼类的系统发育树, 包含 24 种鲟鱼,其中 7 种 (红色中文标识) 分布于中国 ${ }^{[13]}$

Fig.4 Phylogenetic tree based on combined mitochondrial cytochrome b, 12S rRNA, cytochrome c oxidase subunit II , tRNA Phe, tRNA Asp, 16S rRNA, NADH5 and control region gene sequences (eight genes, 4406 sites), including 24 species of Acipenseriforme, with Chinese species indicated by red words ${ }^{[13]}$

\section{2 葛洲坝一一切断了中华鲟的生殖洄游通道}

早在 $1970 \mathrm{~s}$ 科学家就曾预言, “目前正在兴建的葛洲坝水利枢纽将阻隔亲鱼自中、下游上溯进行生殖洄 游, 对中华鲟的资源影响严重, 如不采取适当措施, 甚至将会造成长江中华鲟绝迹” ${ }^{[22]}$.

据估算, 在葛洲坝截流前, 长江中中华鲟的有效补充量每年约 1882 尾, 长江和海洋中育龄 (雌: $13 \sim 34$ 龄, 雄: 8 27 龄) 总资源量为 32260 尾, 其中雄鱼 15310 尾, 雌鱼 16950 尾, 每年长江中的资源量 (捕捞后) 约 1727 尾, 占总资源量的比例约为 $5 \%{ }^{[23]}$.

葛洲坝截流前中华鲟产卵场分布在金沙江下游和长江上游约 $800 \mathrm{~km}$ 的江段, 已报道的产卵场有 16 处 以上. 1981 年葛洲坝建成后, 阻止了中华鲟亲鱼的生殖洄游, 无法上溯到金沙江产卵的中华鲟, 勉强在葛洲 


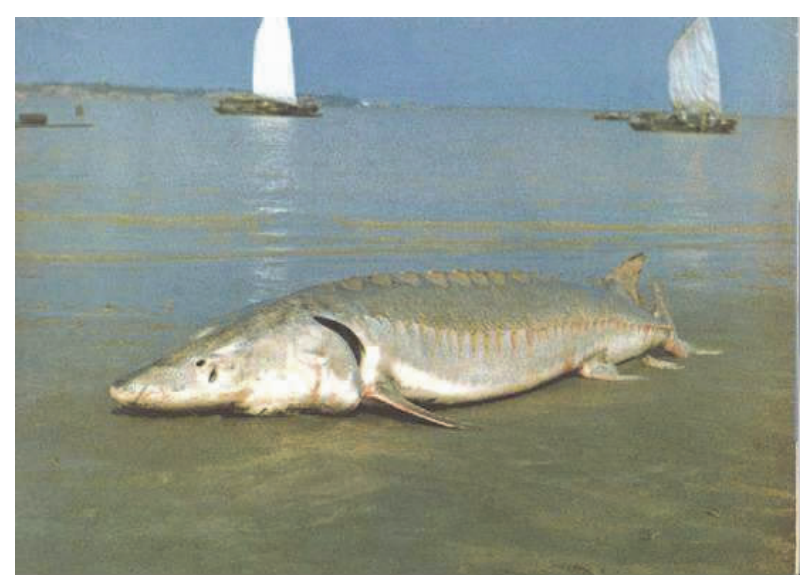

图 5 体型巨大的中华鲟 (Acipenser sinensis $)^{[14]}$

Fig.5 The giant Chinese sturgeon (Acipenser sinensis) ${ }^{[14]}$

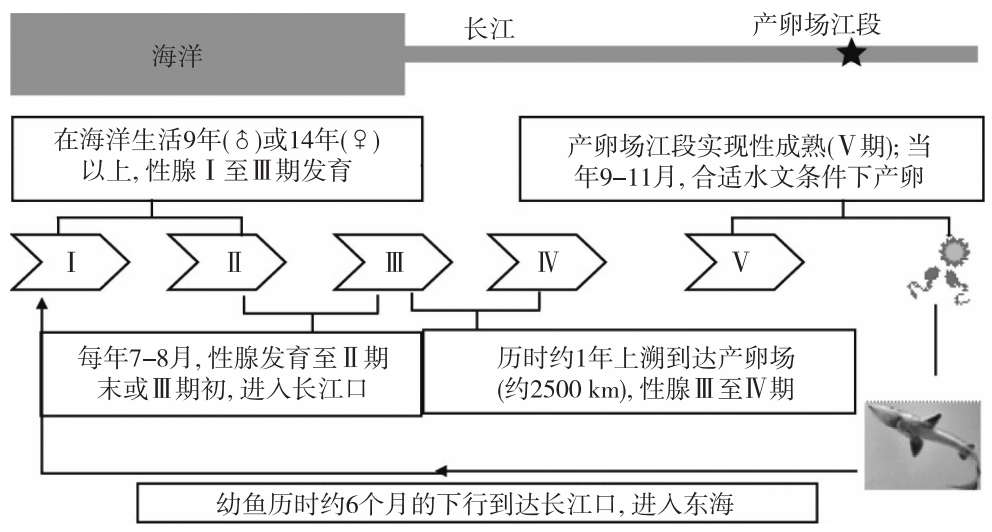

图 6 中华鲟的生活史 ${ }^{[19]}$

Fig.6 Life history of Chinese sturgeon ${ }^{[19]}$

坝下形成了新的产卵场, 主要是宜昌长航船厂至十里红江段, 长度约为 $4 \mathrm{~km}$; 其次是十里红至胭脂坝江段, 长度约为 $5 \mathrm{~km}^{[24]}$. 也有一种说法是葛洲坝截流后仅形成了 1 个新的产卵场, 位于坝下消力池至庙嘴 $2 \mathrm{~km}$ 范围内, 主要集中在南岸笔架山江段的 $1 \mathrm{~km}$ 范围内 ${ }^{[18]}$. 很显然, 中华鲟产卵场的规模大幅萎缩 (图 8). 紧靠 葛洲坝枢纽的坝下江段新形成的中华鲟产卵场被认为对延续中华鲟的自然种群会起到至关重要的作用 ${ }^{[24]}$. Deng 等 ${ }^{[25]}$ 甚至认为, 葛洲坝对中华鲟不是一个威胁. 但 $\mathrm{Xie}^{[26]}$ 预测, 三峡大坝建成后, 可能毁坏这个唯一的 产卵场. 不幸的是, 2013、2015、2017 年均未在葛洲坝下产卵场发现中华鲟产卵. 中华鲟自然繁殖的终结已近 在迟尺!

上溯到金沙江产卵的中华鲟, 曾经是一种重要的经济鱼类,在长江上游的产量每年大约 20000 25000 $\mathrm{kg}$, 譬如, 在宜宾地区每年繁殖季节可形成一个捕捞中华鲟的旺季( 图 9). 葛洲坝截流后的 1981-1982 年, 宜昌和宜宾等地的渔民大量捕杀中华鲟亲鱼, 数量达 2000 余尾, 给中华鲟种群带来很大的伤害 ${ }^{[12]}$. 1983 年 以后, 国家明令禁止了对中华鲟的商业性捕捞. 据黄真理等 ${ }^{[28]}$ 最近的估算, 1981 年 1 月葛洲坝截流导致 1980 年鱼群被葛洲坝阻隔在上游的数量为 660 尾, 下游数量为 349 尾, 1981 年坝下中华鲟捕捞量 1002 尾.

在过去的半个世纪, 中华鲟的繁殖群体经历了急速的衰退过程 ${ }^{[29]}$. 据估计, 1970 s, 长江中的中华鲟繁殖 群体数量 (捕捞后) 尚有 1727 尾, 2005-2007 年期间下降到了 203 257 尾, 到了 2010 年只剩数十尾(图 


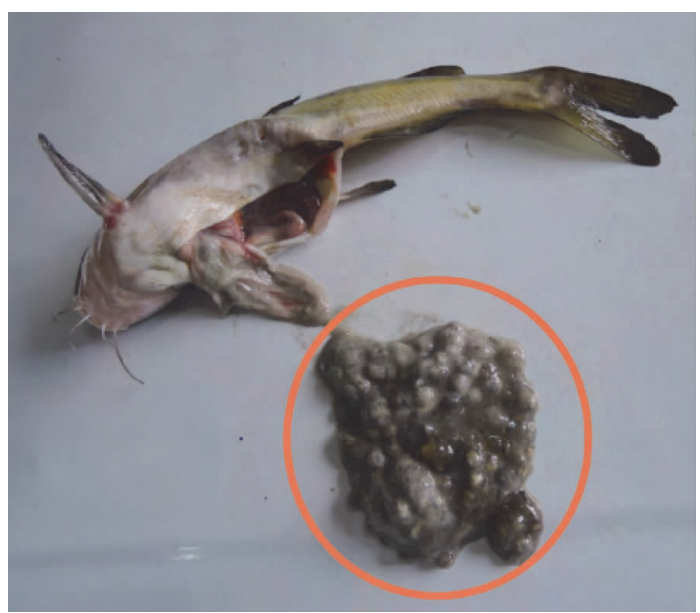

图 7 葛洲坝江段瓦氏黄颡鱼摄食中华鲟卵的情况 (红圈中灰白色颗粒即为中华鲟卵) ${ }^{[21]}$

Fig.7 Acipenser sinensis's eggs were eaten by Pelteobagrus vachelli in the river near Gezhouba Dam, and the gray round pellets in the red circle are eggs of Chinese sturgeon ${ }^{[21]}$

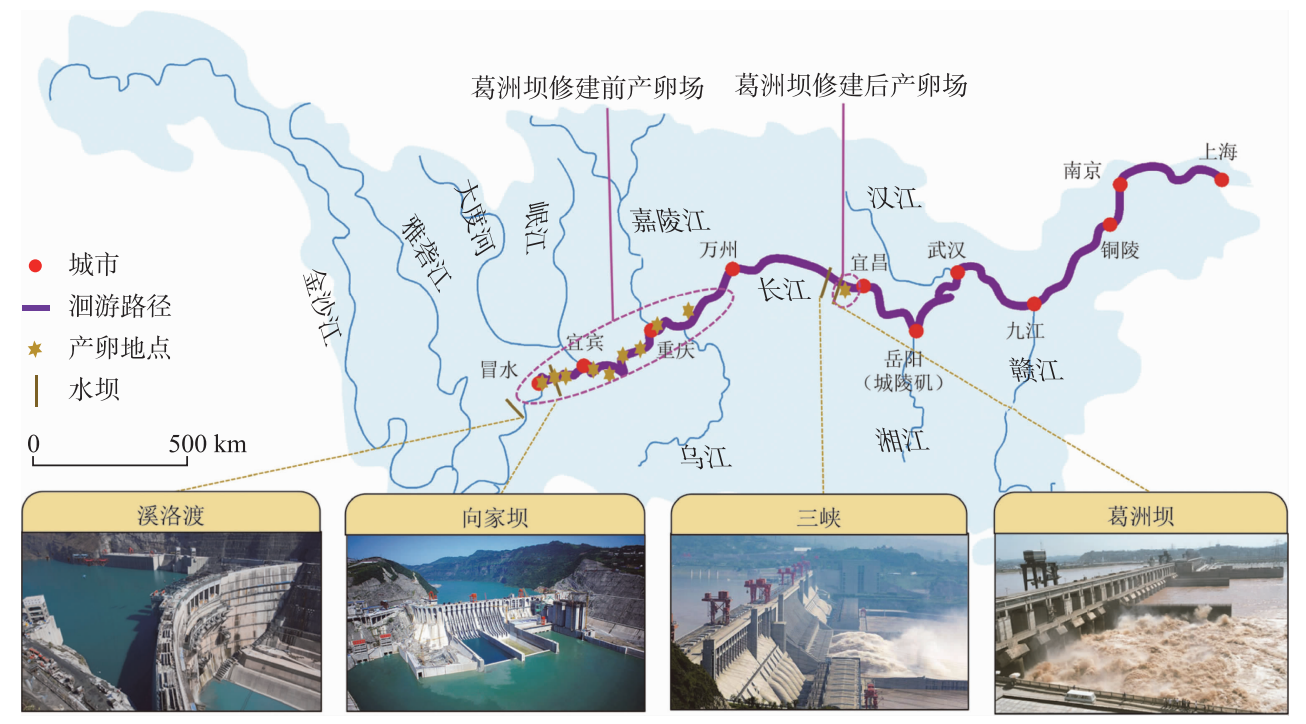

图 8 长江中华鲟产卵场分布示意图 ${ }^{[27]}$

Fig. 8 A sketch of the spawning ground of Chinese sturgeon in the Yangtze River ${ }^{[27]}$

10). 中华鲟已被列人《世界自然保护联盟》( IUCN) 2012 年濒危物种红色名录 ver 3.1一极危 ( CR).

\section{3 梯级大坝一一压死骆驼的最后一根稻草}

三峡蓄水对温度过程产生了影响: 以 2004 年刚蓄水的寸滩站 (位于三峡水库顶部, 是三峡水库的人口 控制站) 和宜昌站 (位于三峡大坝下游 $42 \mathrm{~km}$ 处, 是三峡水库的出口控制站) 为例, $1-2$ 月份水温偏高, $3-5$ 月份水温偏低,7-12 月又显著偏高 (图 11).

水温的变化被认为对中华鲟的产卵产生了重要影响:历史资料表明,葛洲坝建成前, 中华鲟产卵活动大 部分发生在 10 月,在 21 次产卵中只有 3 次发生在 11 月; 葛洲坝建成后至三峡蓄水的 2003 年以前, 中华鲋 在大部分年份有两次繁殖活动, 产卵时间集中在 10 月中下旬; 2003 年以后, 中华鲟在大部分年份只有 1 次 


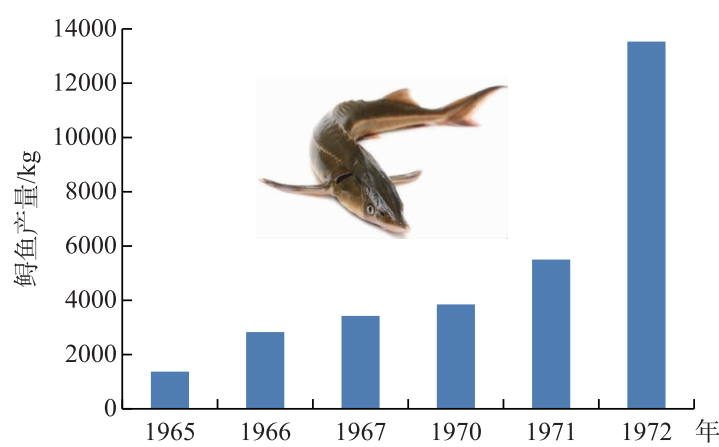

图 9 宜宾渔业社 1965-1972 年期间的 鲟鱼产量(数据来源: 文献 [22])

Fig.9 The sturgeon production of the Yibin

Fishery Association from 1965 to 1972 ( data from reference [22])
产卵活动, 且产卵时间明显推迟 (图 12).

从 2013 年溪洛渡蓄水开始, 梯级水坝强化了 秋季水温的增加, 导致 2013 年开始中华鲟停止产 卵 $^{[27]}$. 上游大坝对下泄水温度的改变进而对中华 鲟产卵的影响日益受到关注 ${ }^{[27,32-38]}$. 王鲁海和黄真 理 ${ }^{[36]}$ 认为, 如果通过梯级水库调度等措施在 10 月 22 日之前将葛洲坝下产卵场的水温降低到 18 $20^{\circ} \mathrm{C}$, 中华鲟野生种群数量可维持在葛洲坝截流后 的水平. 但依笔者之见, 下泄水温升高导致中华鲟 在坝下产卵推迟, 并不是导致中华鲟衰退的决定性 因素, 因为虽然推迟产卵,但毕竟还是能产卵.

黄真理 (私信交流) 认为, 葛洲坝修建前, 正 常繁殖期在 9 月中旬一 11 月中旬 ( 2 个月), 葛洲 坝修建后推迟至 10 月中旬 -11 月中旬 (1 个月) 产卵, 梯级水坝修建后停止了产卵. 这里面, 阻隔

后性腺发育推迟 37 天, 梯级水坝后适宜环境条件 (以水温为主) 从 10 月中旬推迟到 11 月底或 12 月初. 中 华鲟在长江不摄食, 性腺发育推迟后, 如果推迟时间超过容许时间上限(种群水平上为 11 月 15 日), 性腺就 会吸收退化. 因为, 中华鲟的性腺发育和脂肪储量, 不容许长期等待, 什么时候环境条件适合, 什么时候繁殖. 就像女人生孩子, 也有容许时间的上限, 过了 42 周就有生命危险. 因此, 是长江梯级水坝导致了中华鲟的可 能灭绝. 要解决其中关键问题,如性腺退化、温度抑制繁殖行为等问题.
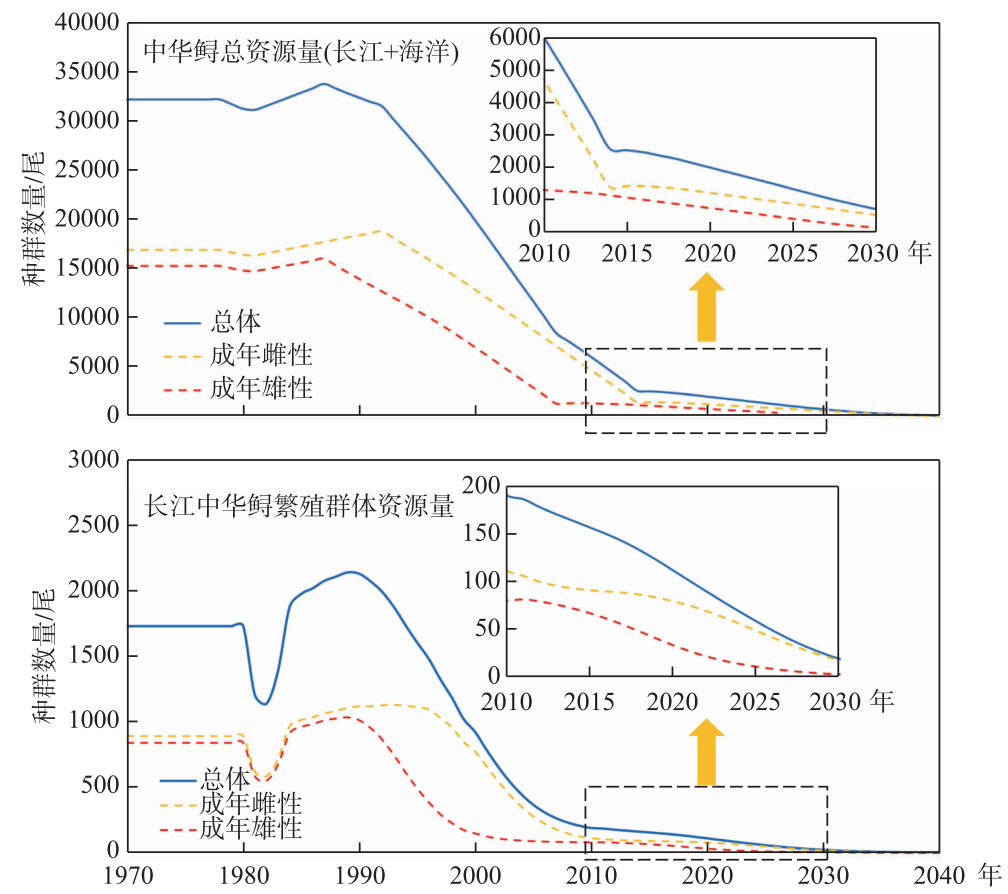

图 10 自 1970s 以来中华鲟繁殖群体在长江中的衰退过程 ${ }^{[27]}$

Fig. 10 The decline of the breeding population of Acipenser sinensis in the Yangtze River since 1970s ${ }^{[27]}$

中华鲟产卵时间推迟为何就会招来灭顶之灾呢? 这实在难以令人信服. 笔者认为, 如果繁殖群体足够 大,这应该不会成为问题. 但事实上, 三峡截流前, 中华鲟的种群数量 (如果按 IUCN 的估算数据) 就已衰减 
到不足 $1970 \mathrm{~s}$ 的 4\%, 大势已去, 温度变化最多不过 是压死骆驼的最后一根稻草罢了!

\section{4 葛洲坝下的产卵场早就失去了意义}

中华鲟的最大寿命可达 40 龄, 最大个体可达 $560 \mathrm{~kg}^{[18]}$. 在葛洲坝截流前的 $1972-1976$ 年, 金沙 江下游产卵场中华鲟成熟个体雄性最小为 9 龄, 雌 性最小为 14 龄, 初次性成熟雄性为 9 22 龄, 雌性为 14 27 龄 ${ }^{[39]}$. 通过繁殖群体的年龄统计来看, 雌性 的平均年龄比雄性高出 5 年左右, 暗示雌性寿命可 能明显高于雄性.

葛洲坝截流发生于 1981 年 1 月 4 日,当年 5 月 23 日大坝关闸蓄水, 因此 1981 年秋季繁殖的中华鲟 才是葛洲坝截流后出生的后代. 譬如, 只有在 1996 年秋季采集的 15 龄样本才是 1981 年出生的 ${ }^{[29]}$.

从图 13 不难看出, 葛洲坝截流之后的新生繁殖 群体补充严重缺乏, 这可由雌雄之间寿命的差异来 解释, 即先行死亡的雄性导致了繁殖群体雌雄性比 的不断攀升. 这其实是中华鲟自然种群进人灭绝状 态的先兆!

\section{5 宁可玉碎, 不能瓦全}

葛洲坝下并不是中华鲟理想的产卵之地, 虽然 每年都有为数不多的个体 (如 $30 \sim 40$ 尾) 在那里产 卵繁殖, 但是很多被拦在坝下的亲鱼其性腺退化 (雄 性约 30\%, 雌性约 70\% ), 有一部分亲鱼向坝上硬 闯, 撞得头破血流伤重而亡(据统计, 1981-1985 年 期间在宜昌江段共捡到死鲟 146 尾, 每年平均 30 尾 左右), 还有一部分亲鱼未产卵而直接降河人海 ${ }^{[18]}$.

葛洲坝工程局中华鲟人工繁殖研究所从 1983 年起, 每年都向长江放流中华鲟苗种, 人工繁殖放流 被视为拯救中华鲟的主要措施 ${ }^{[24]}$. 据统计, 1983 年 以来的 30 多年间, 中华鲟人工繁殖研究所每年都向 长江投放鲟苗 20 万 50 万尾, 以增加长江的种群数 量. 但中华鲟的种群数量并未因人工放流而增加, 估 计人工放流对野生种群的贡献不足 $10 \%{ }^{[40-41]}$.

为了拯救中华鲟, 先后建立了 3 个自然保护区: 江苏省东台市中华鲟自然保护区 (省级, 2000 年)、 上海市长江口中华鲟自然保护区 (市级, 2002 年) 和 湖北省宜昌市中华鲟自然保护区 (国家级, 2004 年). 2015 年 9 月 28 日,农业部发布了《中华鲟拯救 行动计划 $(2015-2030$ 年)》.

令人遗憾的是, 无论是通过人工繁殖放流还是 建立自然保护区, 都未能阻挡中华鲟的日益衰退, 这 个古老的鲟鱼似乎已经卷人了难以逃脱的灭绝漩浴!

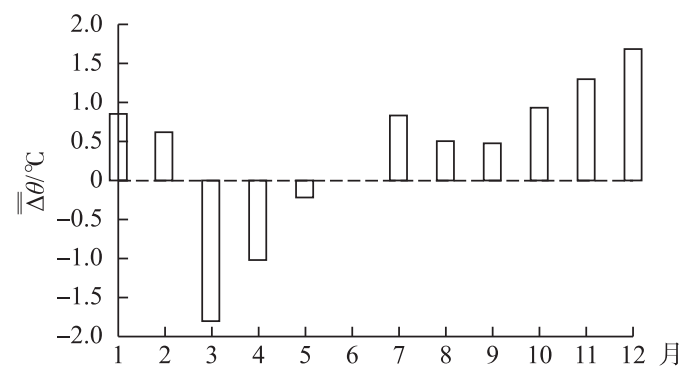

图 11 寸滩站与宜昌站 2004 年月平均 水温差与蓄水前两站多年月平均水温差

$$
\text { 之差 }\left(\overline{\overline{\Delta \theta_{i}}}\right) \text { 的变化 }{ }^{[30]}
$$

Fig.11 The variation of the difference in the monthly averaged temperature $\left(\overline{\overline{\Delta \theta_{i}}}\right)$ between Cuntan and Yichang stations between 2004 and the years before the impoundment ${ }^{[30]}$

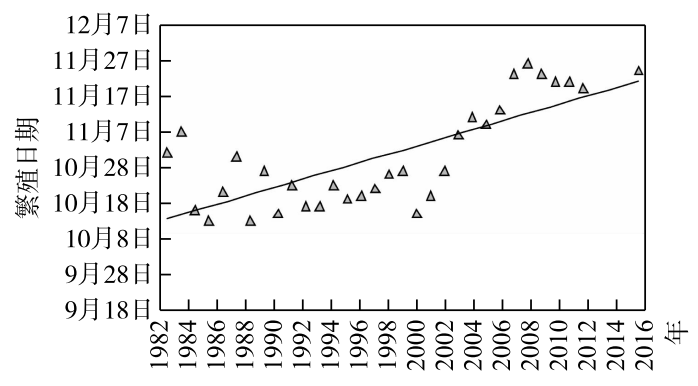

图 12 中华鲟的自然繁殖时间 ${ }^{[31]}$

Fig.12 Dates for natural reproduction of the Chinese sturgeon ${ }^{[31]}$

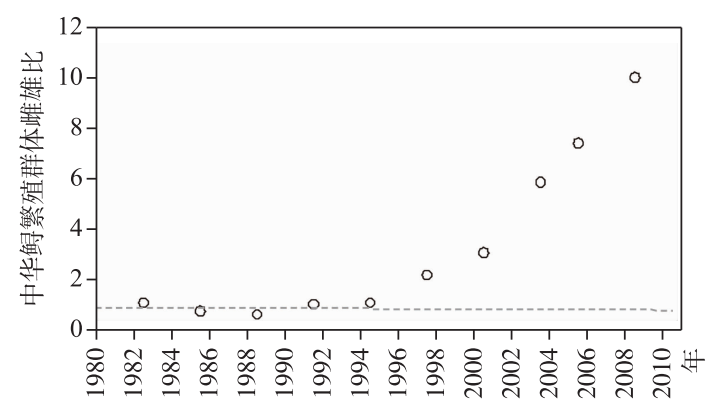

图 13 葛洲坝截流之后坝下宜昌江段中华鲟 产卵群体的雌雄性比变化 ${ }^{[31]}$

Fig. 13 Changes in the sex ratio of the spawning population of Chinese sturgeon after the closure of Gezhouba Dam ${ }^{[31]}$ 


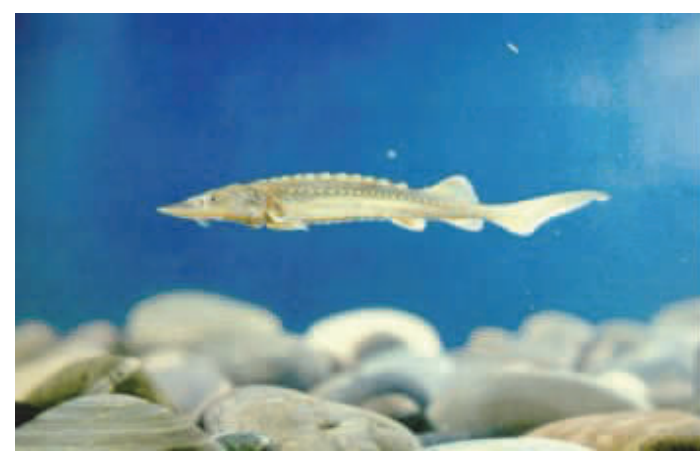

图 14 达氏鲟 ${ }^{[14]}$

Fig.14 Acipenser dabryanus ${ }^{[14]}$

\section{3 达氏鲟一一危危可及}

达氏鲟 (Acipenser dabryanus), 又名长江鲟、沙 腊子, 隶属于鲟形目鲟科鲟属, 仅分布于长江中、上 游, 尤其以宜昌与宜宾之间的干流江段为多, 在上 游金沙江、沱江、嘉陵江等支流和洞庭湖亦有记 载 ${ }^{[22]}$. 达氏鲟是我国的特有物种, 属淡水定居型鲟 种. 达氏鲟可能是中华鲟的陆封型类群 (landlocked form $)^{[42]}$.

\section{1 生活简史}

达氏鲟(图 14) 喜欢在较暗的底层缓流水体中 活动,常栖息于 $8 \sim 10 \mathrm{~m}$ 的江河浅水区,在岩礁、沙 底、卵石区域游七与受食. 冬季在缓流的河道中越 冬,立春后当江水回升至 $12^{\circ} \mathrm{C}$ 以上时开始溯水到上游干支流摄食与繁殖 ${ }^{[43]}$.

达氏鲟雄性 4 7 龄、雌性 5 8 龄达性成熟,一般体长 $0.8 \sim 1.0 \mathrm{~m}$, 体重 5 10 kg. 每年春季 ( $3-4$ 月) 和 秋季 (11-12 月) 产卵, 适宜水温为 $16 \sim 19^{\circ} \mathrm{C}$, 绝对怀卵量 6 万 13 万粒 ${ }^{[39]}$. 性成熟个体上溯至长江上游 (重 庆至宜宾江段) 繁殖, 卵粘着在石砾滩底上发育, 最适孵化温度为 $18 \sim 20^{\circ} \mathrm{C}^{[44]}$. 与中华鲟和白鲟相比, 达氏 鲟体型要小得多,记载的最大个体也才 $16 \mathrm{~kg}^{[18]}$.

达氏鲟的食物主要是底栖无脊椎动物 (摇蚊幼虫、蜻蜓幼虫、蜉蝣幼虫和蛹、蚬、寡毛类等), 也摄食水生 植物碎屑、藻类 (硅藻和丝状藻类) 和腐殖质等, 有少数个体捕食鱼苗和幼鱼 ${ }^{[22]}$.

\section{2 种群的衰退与濒危}

达氏鲟的自然种群并不大, 虽然它曾是长江上游的重要经济鱼类, 但 1980s 以来, 达氏鲟的种群数量已 十分稀少. 1984-2010 年的统计数据显示, 每年平均仅有十多尾达氏鲟被误捕, 特别是 1995 年以来, 在葛洲 坝下就再也没有捕捞到过 ${ }^{[45-46]}$. 由此判断, 达氏鲟在葛洲坝下游江段可能已经绝迹, 目前仅零星分布于四川 境内的长江上游江段.

导致达氏鲟种群衰退的原因有过度捕捞和水利工程等. 譬如, 在沱江的内江河段, 1950s 仅有渔船 500 艘, 到 1985 年增加到 2000 艘. 又如, 在岷江乐山河段, 流刺网不分昼夜密集作业. 1981 年建成的葛洲坝和 2003 年建成的三峡大坝大大压缩了达氏鲟的生存空间,迫使它们只能生活于坝上江段,而 2008 年建成的向 家坝正好在达氏鲟产卵场的中间,其巨大影响不言而喻.

1988 年达氏鲟被列为国家 I 级保护野生动物. 1996 年, 世界自然保护联盟( IUCN) 将达氏鲟评定为极 危 ( critically endangered, CR) 物种. 据称, 自 2000 年以后再没有监测到达氏鲟的自然繁殖, 达氏鲟的野生种 群基本绝迹, 人工保种的野生个体仅存几十尾. 2018 年 5 月 16 日, 农业农村部发布了《长江鲟(达氏鲟) 拯 救行动计划 (2018-2035 年)》. 人工放流依然延续着人们企图恢复达氏鲟野外种群的梦想, 如 2019 年 5 月 21 日, 中国水产科学研究院长江水产研究所在长江上游的宜宾江段放流了 60 尾达氏鲟亲本、1000 尾 2 龄达 氏鲟.

\section{4 白鲟一已经绝灭?}

白鲟 (Psephurus gladius) 隶属于鲟形目匙吻鲟科白鲟属, 主要分布于四川宜宾以下至河口的长江干流和 支流 (沱江、岷江、嘉陵江) 以及大型通江湖泊 (洞庭湖、鄱阳湖) 中, 也见于黄河、钱塘江和角江, 东海和南海 亦有分布 ${ }^{[18]}$.

早在 1862 年,英国“扬子江上游探险队”的托马斯・布莱基斯顿在湖北咸宁市附近记述了白鲟: “体长 3 英尺, 嘴部呈钟形, 向外突出, 鼻子或触角伸出头部 12 英寸”,并绘有白鲟整体及部分的素描图 ${ }^{[47]}$.

\section{1 生活简史}

白鲟是中国最大的淡水鱼类, 个体长度一般在 $2 \mathrm{~m}$ 左右, 重量在 $25 \mathrm{~kg}$ 以上. 白鲟个体的最大记录体重 
为 $908 \mathrm{~kg}^{[54]}$,体长为 $7 \mathrm{~m}$, 是世界淡水鱼类体长的最高记录.

白鲟 (图 15) 分布于长江、钱塘江以及黄海和东海 ${ }^{[48]}$. 在长江干流, 白鲟栖息于中下层, 偶亦进人沿江大 型湖泊中, 大的个体多栖息于干流的深水河槽, 幼鱼则常到支流、港道, 甚至到长江口的半咸水区受食.

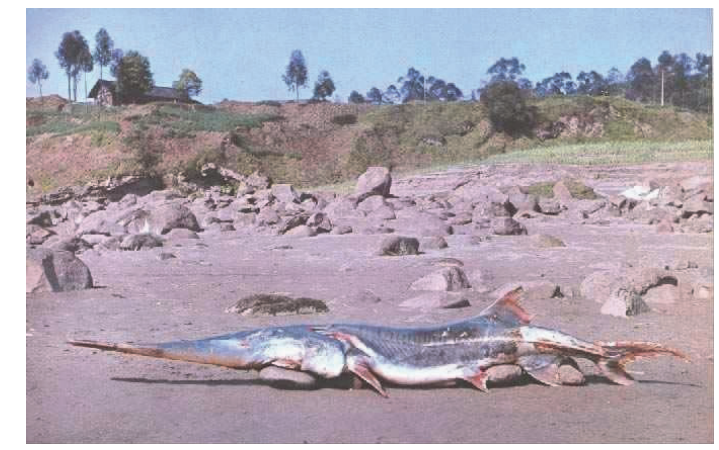

图 15 已经绝灭的世界上最长的淡水鱼一白鲟 (Psephurus gladius) ${ }^{[14]}$

Fig.15 Extinct Chinese paddlefish, the longest fish in the world ${ }^{[14]}$

白鲟为凶猛性鱼类, 成鱼和幼鱼均以鱼类为食: 在重庆、涪陵解剖的 8 尾鱼中均以铜鱼为食, 在安庆解 剖的 5 尾鱼主要摄食鲚鱼以及少数虾、蟹 ${ }^{[22]}$.

白鲟初次性成熟年龄较迟, 雄鱼为 5 6 龄, 雌鱼为 7 8 龄. 每年春季 (3-4 月) 溯江产卵, 产卵场位于 四川省沾州以上,集中于江安县附近的长江河段和宜宾柏树溪附近的金沙江河段. 成熟亲鱼多栖息在水流 较急、水较深、底质多为岩石或鹅卵石的河段 ${ }^{[49]}$. 白鲟产沉性卵, 产卵水温为 $18 \sim 20^{\circ} \mathrm{C} .7 \sim 15$ 龄䧳性白鲟的 绝对繁殖力为 17.8 万 $~ 78.8$ 万粒 (平均为 35.9 万粒) ${ }^{[50]}$.

\section{2 种群的衰退与濒危}

在上游繁殖的白鲟一部分滞留在上游干支流内生长, 另有一部分漂流到中下游, 有的一直抵达长江口崇 明附近受食. 葛洲坝枢纽兴建后, 在长江上游生活的白鲟仍能繁殖, 但在中下游成长的白鲟无法上溯到上游产 卵场, 滞留于葛洲坝宜昌江段的白鲟虽然能够发育成熟, 但由于亲鲄数量很少, 未观察到在坝下江段的自然繁 殖; 在上游繁殖的一部分白鲟仔、幼鱼可以通过泄水闸漂流下坝, 因此, 在 1983-1988 年期间, 每年均可在崇明 收集到白鲟幼鱼,但数量呈逐渐减少的趋势 ${ }^{[24]}$.

白鲟的产量曾达 $25 \mathrm{t}$ 左右, 但 1980s 以来, 种群数 量大幅下降(图 16). 白鲟已很难捕获到, 1992 年在长 江上游重庆江段捕获了 2 头, 2002 年在长江下游江苏 南京江段捕获到一尾雌鱼, 2003 年在长江上游的宜宾 江段捕获了一尾长 $3.5 \mathrm{~m}$ 的雌鱼. 之后就再也没有见 到过白鲟. 据估计, 白鲟于 1993 年功能性灭绝 (functional extinction) , 2005-2010 年期间完全灭绝 ${ }^{[51]}$.

1983 年白鲟被列为国家 I 级野生保护动物, 1996 年, IUCN 将白鲟评定为极危物种. 水利工程对生殖洄 游的阻断、过度捕捞以及长江鱼类资源量的下降可能 是导致白鲟濒危的重要因素.

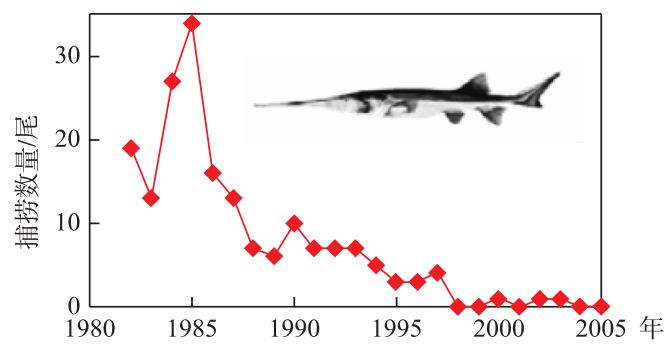

图 16 1981-2005 年期间葛洲坝下的 白鲟捕捞数量 ${ }^{[51]}$

Fig.16 Catch of the Chinese paddlefishes during 1981 and 2005 ${ }^{[51]}$

\section{5 为什么长江的鲟鱼都苃炭可危?}

鲟鱼虽然古老, 但却十分稀少. 譬如, 全世界的鲤形目鱼类有 3000 多种, 而全世界的鲟形目鱼类却只有 约 27 种. 这表明鲟鱼的分化能力极其有限, 也预示其生态位的特殊性, 以及极为有限的生态可塑性. 鲟鱼的 珍贵已是不争的事实(图 17). 


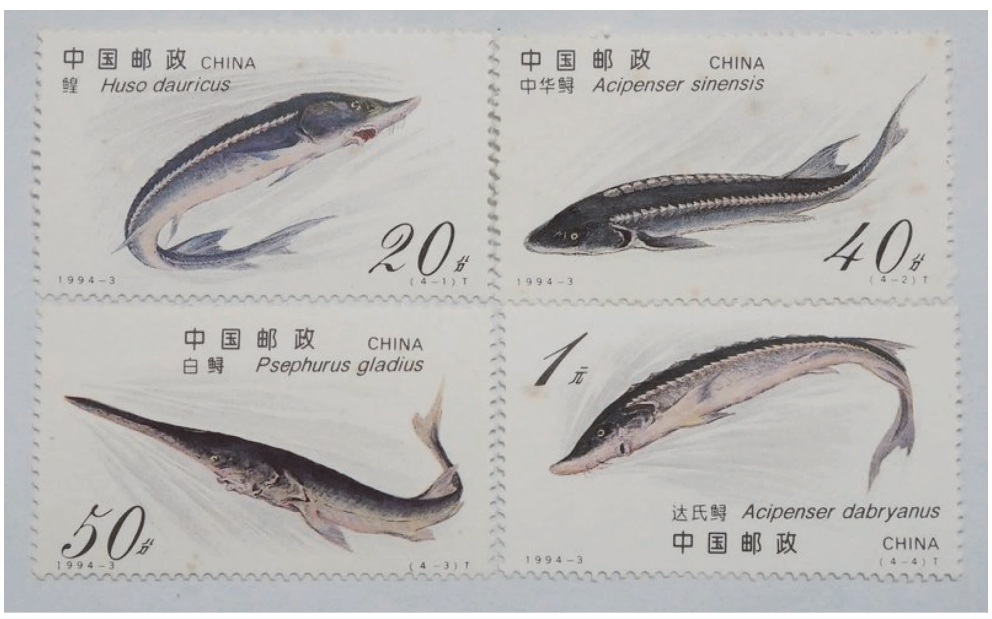

图 171994 年发行的鲟鱼(鳇、中华鲟、白鲟和达氏鲟) 邮票

Fig. 17 The stamps of sturgeons (Huso dauricus, Chinese sturgeon,

Chinese paddlefish and Acipenser dabryanus) issued in 1994

虽然在长江中的 3 种鲟鱼的生活史特征或多或少都有些差别 (表 1), 但繁殖方面却有惊人的相似之处: 产卵场都在上游相似的江段, 都是激流环境, 底质特征都是多砾石, 都产沉性・粘性卵, 虽然产卵时间不 同一一达氏鲟和白鲟在春季, 而中华鲟在秋季. 三种鲟鱼寻求在上游的急流环境中产卵, 难道是因为能从那 里得到什么欢乐? 这应该是一种自然选择的结果, 即它们嗜好的可能不是激流, 而是急流环境中的砾石, 因 为它们产出的卵都需粘附在石块上或沉落于石缝中去孵化, 这可能最有利于安全孵化与幼鱼成活, 就被固 化成了秉性. 而在葛洲坝下, 鲜有江段能满足这样的条件, 因此, 自 1980s 初葛洲坝建成以来, 鲟鱼就迎来了 灭顶之灾. 虽然中华鲟在葛洲坝下形成了新的产卵场, 但其规模却大大萎缩, 现在看来, 这个新的产卵场未 必就那么适合中华鲟.

表 1 长江中 3 种鲟鱼生活史特征的比较

Tab.1 A comparison of the life history traits among the three species of sturgeons in the Yangtze River

\begin{tabular}{|c|c|c|c|}
\hline 生活史特征 & 中华鲟 & 达氏鲟 & 白鲟 \\
\hline 主要食物 & 在河口, 主食虾蟹和小鱼 ${ }^{[22]}$ & 底栖无脊椎动物 [22] & 多为鱼, 偶有虾蟹 [22] \\
\hline 生态类型与分布 & $\begin{array}{l}\text { 海河洄游型, 除在河流中繁殖 } \\
\left.\text { 外, 其余时间在海洋中生活 }{ }^{22}\right]\end{array}$ & $\begin{array}{l}\text { 淡水鱼类, 在中上游干流及 } \\
\text { 沿江大型湖泊生活 }{ }^{[22]}\end{array}$ & $\begin{array}{l}\text { 长江、钱塘江以及黄海和 } \\
\text { 东海 } \\
\text { [48] }\end{array}$ \\
\hline 产卵地点 & $\begin{array}{l}\text { 金沙江下游和川江上段 (宜宾一 } \\
\text { 屏山) }\end{array}$ & 重庆至宜宾江段 ${ }^{[22]}$ & 金沙江下游的宜宾江段 [24] \\
\hline 卵的类型 & 沉性·粘性卵 ${ }^{[22]}$ & 沉性·粘性卵 ${ }^{[48]}$ & 沉性·粘性卵 ${ }^{[55]}$ \\
\hline 产卵场水文与底质 & 急流,多砾石 ${ }^{[52-53]}$ & 急流,多砾石 ${ }^{[22]}$ & 急流,多砾石 $[48]$ \\
\hline 最初成熟年龄 & 雄性 12 龄, 雌性 14 龄[52] & 雄性 4 龄, 雌性 6 龄 [24] & 雄性为 5 龄, 雌性为 7 龄 [24] \\
\hline 最初成熟时体重 & 雄性 $68 \mathrm{~kg}$, 雌性 $130 \mathrm{~kg}^{[52]}$ & 雄性 $5 \mathrm{~kg}^{[22]}$ & 雄性 $12.6 \mathrm{~kg}$, 雌性 $28.3 \mathrm{~kg}^{[24]}$ \\
\hline 繁殖季节 ～～～～～～～～～～ & 秋季 ( 10 月中旬一 11 月中旬) ${ }^{[24]}$ & 估计在春季 ${ }^{[22]}$ & 春季(3-4月) ${ }^{[24]}$ \\
\hline 产卵时水温 & $17.0 \sim 19.5^{\circ} \mathrm{C}^{[24]}$ & $16.0 \sim 19^{\circ} \mathrm{C}^{[24]}$ & $18.3 \sim 20.0^{\circ} \mathrm{C}^{[18]}$ \\
\hline 孵化时间 (温度) & $5 \sim 6$ 昼夜 $\left(17 \sim 18^{\circ} \mathrm{C}\right)^{[53]}$ & - & - \\
\hline 孵出到摄食所需时间 & 9 天 $^{[53]}$ & - & - \\
\hline 绝对繁殖力 & $\begin{array}{l}63.4 \text { 万 120.5 万粒 }(\text { 体长 } 2.54 \sim \\
3.25 \mathrm{~m} \text {, 体重 } 159 \sim 325 \mathrm{~kg})^{[22]}\end{array}$ & $\begin{array}{l}12.9 \text { 万粒 (体长 } 0.97 \mathrm{~m} \text {, 体重 } \\
8.5 \mathrm{~kg})^{[22]}\end{array}$ & $\begin{array}{l}30 \text { 万粒以上（体重 } 30 \sim \\
35 \mathrm{~kg})^{[22]}\end{array}$ \\
\hline 最大寿命 & 40 龄 $[18]$ & - & - \\
\hline 最大体重 & $560 \mathrm{~kg}^{[18]}$ & $16 \mathrm{~kg}^{[24]}$ & $908 \mathrm{~kg}^{[54]}$ \\
\hline
\end{tabular}

一表示无数据. 
水坝对长江鲟鱼的致命打击无容置疑 ${ }^{[56]}$, 从地质历史演化的角度看亦是如此 ${ }^{[57]}$, 因为适应并不是万能 的, 不然, 历史上就不会出现物种的绝灭, 这与物种自身的适应能力、时间以及环境的变幅等诸多因素均有 关系. 成熟的中华鲟并不需要在长江中摄取食物 (虽然它在浅海的索饵场或多或少也遭受到了破坏), 因此, 中华鲟种群的衰退可能只能归因于生殖洄游的阻隔. 它们无法在葛洲坝上游长期生存下去, 因为它们的幼 鱼必须回到大海中去摄食与肥育. 而在葛洲坝下游, 又没有它们适宜的产卵之地. 因此, 笔者悲观地预测, 中 华鲟的灭绝决不会久远,这个古老的物种已无回天之力.

因为达氏鲟无需到大海中去肥育, 从理论上来说, 只要上游的产卵场存在以及饵料充足, 它就可能在上 游水系中残存下来. 但因为上游的个体无法到中下游及其通江湖泊中摄食, 达氏鲟的生存空间已被大大压 缩. 白鲟属于咸淡水双向迁徙型, 早期幼鱼需要在海洋生活 (河口捕捞到幼鱼), 幼鱼生长到一定阶段回到长 江. 因此,一方面葛洲坝对它的影响会很显著, 另一方面又由于它体型更大, 且是肉食性, 因此, 灭绝的风险 更大. 事实上, 现在很难寻受白鲟的身影, 被认为已经功能性灭绝了.

鲟鱼体型巨大,一个完整的生活周期往往需要巨大的空间, 特别是有些环境的不可替代性往往会成为 它们的致命之处, 这种关键环境的破坏往往会导致灭顶之灾, 如中华鲟体型巨大, 其生活周期需洄游数千 里, 而且还需到金沙江的激流中去繁殖, 将卵粘附于砾石或掉落于砾石缝隙之中. 其他两种鲟鱼也选择了类 似的产卵环境.

水温、水流以及砾石……哪一个都有可能成为这些古老鲟鱼的繁殖启动信号, 也许是它们的组合, 但这 些环境信号的一致性所表征的产卵场却不是那么轻易能够重组的, 因为它是在漫长的自然历史中, 鲟鱼适 应气候、地质过程以及河流地貌不断演变的产物, 藉此, 中华鲄形成了对河流自然进程的特殊感知, 并如此 根深蒂固以致无可替代. 因此, 葛洲坝与三峡大坝的阻隔, 使中华鲟永远丧失了适宜的产卵场所. 白鲄的生 存空间似乎也是从上游一直延伸到河口, 只是不像中华鲄那样必须到大海中去摄食生长, 因而但大坝的阻 隔也使它们索饵肥育的空间大大压缩. 达氏鲟由于体型相对较小, 也主要在中上游索覀生长, 因而可能是在 3 种鲟鱼中生存状态相对较好的一种,或许是最有可能在上游环境中残存下来的鲟鱼.

这是一条延绵数千公里并通向海洋的河流, 从古至今都是所有物种共享着的, 河首河尾, 河滩河心, 此 处彼处……在这个壮观的剧院中, 它们用各自的音符弹奏着一首共同的河流之歌,荡漾在无尽的河谷之中, 即便我们倾心地观察与思考,也未必能完全理解它. 中华鲟和白鲟的乐曲就谱写在大海与金沙江之间的穿 越中, 保持着几乎不变的生死韵律一一受食、洄游、繁殖和死亡一世世世代代, 生生不息……在苦难面前, 它 们没能屈服, 其结果, 曲终鲟散正在悄然而至, 感知绝技即将化为寓言!

\section{6 参考文献}

[ 1 ] IUCN ed. The IUCN red list of threatened species. Version 2016-3, 2016. http://www.iucnredlist.org.

[ 2 ] Ludwig A. A sturgeon view on conservation genetics. European Journal of Wildlife Research, 2006, 52( 1 ) : 3-8. DOI: 10. $1007 / \mathrm{s} 10344-005-0006-2$.

[ 3 ] Lu LW, Li DQ, Yang LF. Notes on the discovery of Permian Acipenseriformes in China. Chinese Science Bulletin, 2005, 50(10)：1058-1059. [卢立伍, 李大庆, 杨良锋. 中国发现二叠纪鲟形鱼类化石. 科学通报, $2005, \mathbf{5 0}(10)$ : 1058-1059.]

[ 4 ] Jin F. Middle to late Mesozoic sturgeon-like fish fossils in northern Hebei and western Liaoning. In: Chen PJ, Jin F eds. Jehol Biota (Palaeoworld). Hefei : University of Science and Technology of China Press, 1999: 188-280. [ 金帆. 冀北辽 西中生代中晚期鲟形鱼类化石. 合肥: 中国科学技术大学出版, 1999: 188-280.]

[ 5 ] Liu XT, Zhou JJ. A new sturgeon from the Upper Jurassic of Liaoning, North China. Vertebrata Pal Asiatica, 1965, 3(3) : 237-255. [刘宪亭, 周家健. 辽宁北票晚侏罗世鲟类一新科. 古脊椎动物与古人类, 1965, 3(3): 237-255.]

[ 6 ] Bai YJ. A new Peipiaosteus from Fengning of Hebei, China. Vertebrata Palasiatica, 1983, 21 (4) : 341-346, $367-368$. [白勇军. 河北丰宁北票鲟一新种. 古脊椎动物与古人类, 1983, 21(4): 341-346, 367-368.]

[ 7 ] Gardiner BG. Sturgeons as living fossils. In: Eldredge N, Stanley SM eds. Living fossils. New York: Springer-Verlag, 1984 : 148-152.

[ 8 ] Birstein V, Hanner R, De Salle R. Phylogeny of the Acipenseriformes: Cytogenetic and molecular approaches. Environ- 
mental Biology of Fishes, 1997, 48(1/2/3/4) : 127-155. DOI: 10.1023/A:1007366100353.

[ 9 ] Sowerby ADeC. The Yangtze beaked sturgeon. China J Sci Arts, 1925, 3: 86-88.

[10] Peng ZG, Ludwig A, Wang DQ et al. Age and biogeography of major clades in sturgeons and paddlefishes (Pisces: Acipenseriformes). Molecular Phylogenetics and Evolution, 2007, 42(3) : 854-862. DOI: 10.1016/j.ympev.2006.09.008.

[11] Billard R, Lecointre G. Biology and conservation of sturgeon and paddlefish. Reviews in Fish Biology and Fisheries, 2000, 10(4) : 355-392. DOI: 10.1023/A:1012231526151.

[12] Yu ZT. Preliminary evaluation on the impacts of large water conservancy project on fish resources in the Yangtze River ( II ). Reservoir Fisheries, 1988, 9(3) : 24-27. DOI: 10.15928/j.1674-3075.1988.03.008. [余志堂. 大型水利枢纽对 长江鱼类资源影响的初步评价 (二). 水利渔业, 1988, 9(3) : 24-27.]

[13] Krieger J, Hett AK, Fuerst PA et al. The molecular phylogeny of the order Acipenseriformes revisited. Journal of Applied Ichthyology, 2008, 24(s1) : 36-45. DOI: 10.1111/j.1439-0426.2008.01088.x.

[14] Huang HJ, Yue PQ, Yu XF et al eds. The freshwater fishes of China in coloured illustrations. Shanghai: Shanghai Scientific \& Technical Publishers, 1982. [黄宏金, 乐佩琦, 郁雪芳等. 中国淡水鱼类原色图集. 上海: 上海科学技术出版 社, 1982.]

[15] Yu ZT, Xu YG, Deng ZL et al eds. Study on reproductive ecology of Zhonghua sturgeon (Acipenser sinensis Gray) downstream of the Gezhouba Hydroelectric Project. Transactions of the Chinese Ichthyological Society (Vol. 5). Beijing: Science Press, 1986: 1-14. [余志堂, 许蕴玕, 邓中粼等. 葛洲坝水利枢纽下游中华鲟繁殖生态的研究. 鱼类学论文集 (第五辑). 北京: 科学出版社, 1986: 1-14.]

[16] Wei Q, Ke F, Zhang J et al. Biology, fisheries, and conservation of sturgeons and paddlefish in China. Environ Biol Fish, 1997, 48: 241-255.

[17] Huang ZL. Drifting with flow versus self-migrating-how do young anadromous fish move to the sea? iScience, 2019, 19: 772-785. DOI: $10.1016 /$ j.isci.2019.08.029.

[18] Zhuang P, Wang YH, Li SF et al eds. Fishes of the Yangtze estuary. Shanghai: Shanghai Scientific \& Technical Publishers, 2006. [庄平, 王幼槐, 李圣法等. 长江口鱼类. 上海: 上海科学技术出版社, 2006. ]

[19] Wang HZ, Tao JP, Chang JB. Endangered levels and conservation options evaluations for Chinese sturgeon, Acipenser sinensis Gary. Resources and Environment in the Yangtze Basin, 2019, 28(9): 2100-2108. [王鸿泽, 陶江平, 常剑波. 中华鲟濒危状况与物种保护对策的评估分析. 长江流域资源与环境, 2019, 28(9): 2100-2108.]

[20] Yu GL, Liu J, Xu YG et al. Estimation on abundance of benthonic fishes preying on eggs of Chinese sturgeon in reach below the Gezhouba Dam in the Yangtze River. Acta Hydrobiologica Sinica, 2002, 26(6) : 591-599. [虞功亮, 刘军, 许蕴 玕等. 葛洲坝下游江段中华鲟产卵场食卵鱼类资源量估算. 水生生物学报, 2002, 26(6) : 591-599.]

[21] Wu JM, Wang CY, Zhang SH et al. From continuous to occasional: Small-scale natural reproduction of Chinese sturgeon occurred in the Gezhouba spawning ground, Yichang, China. Journal of Fishery Sciences of China, 2017, 24(3): 425431. DOI: 10.3724/SP.J.1118.2017.17095. [ 吴金明, 王成友, 张书环等. 从连续到偶发: 中华鲟在葛洲坝下发生小 规模自然繁殖. 中国水产科学, 2017, 24(3) : 425-431.]

[22] Fish Research Laboratory, Hubei Institute of Hydrobiology ed. Fishes of the Yangtze River. Beijing: Science Press, 1976. [湖北省水生生物研究所鱼类研究室. 长江鱼类. 北京:科学出版社, 1976.]

[23] Wang LH, Huang ZL, Ren JY et al. An age-structured population model of the Chinese sturgeon (Aciperser sinensis). Journal of Fisheries of China, 2018, 42 (8) : 1263-1272. DOI: 10.11964/jfc.20170410778. [王鲁海, 黄真理, 任家盈 等. 基于年龄结构的中华鲄资源量估算方法. 水产学报, 2018, 42(8) : 1263-1272.]

[24] Environmental Evaluation Department of Chinese Academy of Sciences and Changjiang Water Resources Protection Institute ed. Report on Environmental Impacts of the Three Gorges Hydro-project at the Yangtze River, 1991. [中国科学院环境评 价部和长江水资源保护研究所. 长江三峡水利枢纽环境影响报告书, 1991.]

[25] Deng X, Deng ZL, Mingyan C. Spawning population characteristics of Acipenser sinensis in Yangtze River just below Gezhoba Dam. In: Williot P ed. Proceedings of the First International Symposium on sturgeons. Bordeaux (Gironde, France), 1991: 235-242.

[26] Xie P. Three-Gorges Dam: Risk to ancient fish. Science, 2003, 302 (5648) : 1149-1151. DOI: 10.1126/science.302. 5648.1149b. .

[27] Huang ZL, Wang LH. Yangtze dams increasingly threaten the survival of the Chinese sturgeon. Curr Biol, 2018, 28: 
3640-3647.

[28] Huang ZL, Wang LH, Ren JY. Study on the spawning population fluctuation of Chinese sturgeons around the closure of Gezhouba Dam. Scientia Sinica: Technologica, 2017, 47(8): 871-881. [黄真理, 王鲁海, 任家盈. 葛洲坝截流前后 长江中华鲟繁殖群体数量变动研究. 中国科学:技术科学, 2017, 47(8): 871-881.]

[29] Wei QW, Chen XH, Yang DG et al. Variations in spawning stock structure of Acipenser sinensis within 24 years since damming of Gezhouba Dam. Journal of Fishery Sciences of China, 2005, 12(4) : 452-457. [危起伟, 陈细华, 杨德国等. 葛 洲坝截流 24 年来中华鲟产卵群体结构的变化. 中国水产科学, 2005, 12(4): 452-457.]

[30] Yu WG, Xia ZQ, Yu GR et al. Water temperature variation in Three-Gorges Reservoir and its influences on procreation of Chinese sturgeons. Journal of Hohai University: Natural Sciences, 2007, 35(1): 92-95. [余文公, 夏自强, 于国荣等. 三峡水库水温变化及其对中华鲄繁殖的影响. 河海大学学报:自然科学版, 2007, 35(1) : 92-95.]

[31] Chen XJ, Wang D, Yu XB et al eds. The impacts of the operation of the Three Gorges project on the aquatic animals in the middle and lower reaches (Chapter 6)//Xie P ed. Evaluation on the impacts of the Three Gorges Dam on the wetland ecosystems in the middle and lower reaches of the Yangtze River. Beijing: Science Press, 2018: 124-162. [陈小娟, 王丁, 于秀波等. 三峡工程运行对中下游水生动物的影响 (第六章)//谢平. 三峡工程对长江中下游湿地生态系统的影 响评估. 武汉: 长江出版社, 2018: 124-162.]

[32] Chen YB. Studies on the influence of the operation of the Three Gorges Dam on reproduction of the Chinese sturgeon, Acipenser sinensis: the ecohydrological mechanism and conservation [Dissertation]. Wuhan: Institute of Hydrobiology, Chinese Academy of Sciences, 2007. [ 陈永柏. 三峡水库运行影响中华鲟繁殖的生态水文学机制及其保护对策研究 [学位论文]. 武汉: 中国科学院水生生物研究所, 2007.]

[33] Deng Y, Xiao Y, Tuo YC et al. Influence of Three Gorges Reservoir on water temperature between Yichang and Jianli. Advances in Water Science, 2016, 27(4) : 551-560. [邓云, 肖尧, 脱友才等. 三峡工程对宜昌一监利河段水温情势的 影响分析. 水科学进展, 2016, 27(4): 551-560.]

[34] Liao XL, Zhu B, Chang JB. Study on conservation of Chinese sturgeon. Yangtze River, 2017, 48(11): 16-20, 35. [ 廖小 林, 朱滨, 常剑波. 中华鲟物种保护研究. 人民长江, 2017, 48(11): 16-20, 35.]

[35] Du LX, Niu LH, Huang T. Analysis on the characteristics of water temperature changes and the influences of Three Gorges Reservoir. Express Water Resources \& Hydropower Information, 2017, 38: 58-63. [杜林霞, 牛兰花, 黄童. 三峡水库水 温变化特性及影响分析. 水利水电快报, 2017, 38: 58-63.]

[36] Wang LH, Huang ZL. What is actually the main cause for the survival crisis of Chinese sturgeon? J Lake Sci, 2020,32 (4) : 924-940. DOI: 10.18307/2020.0403. [王鲁海, 黄真理. 中华鲟(Acipenser sinensis)生存危机的主因到底是什 么? 湖泊科学, $2020,32(4): 924-940$.

[37] Hui EQ, Mao JQ, Dai HC. Effects of temperature variation at upstream of the Three Gorges Reservoir on Chinese sturgeon spawning reach. Advances in Science and Technology of Water Resources, 2018, 38: 44-48. [惠二青, 毛劲乔, 戴会超. 上游水库水温情势变化对中华鲟产卵江段水温的影响. 水利水电科技进展, 2018, 38: 44-48.]

[38] Zhang H, Kang MH, Wu JM et al. Increasing river temperature shifts impact the Yangtze ecosystem: Evidence from the endangered Chinese sturgeon. Animals, 2019, 9: 583. DOI: 10.3390/ani9080583.

[39] The Changjiang Aquatic Resources Survey Grouo, Sichuan Province ed. The biology of the sturgeons in Changijiang and their artificial propagation. Chengdu: Sichuan Scientific and Technical Publishing House, 1988. [四川省长江水产资源 调查组. 长江鲟鱼类生物学及人工繁殖研究. 成都: 四川社会科学技术出版社, 1988.]

[40] Chang JB. Structure and dynamics of the spawning stock of Chinese sturgeon, Acipenser sinensis, in the Yangtze River [Dissertation]. Wuhan: Institute of Hydrobiology, Chinese Academy of Sciences, 1999. [ 常剑波. 长江中华鲟产卵群体 结构和资源变动 [学位论文]. 武汉: 中国科学院水生生物研究所, 1999.]

[41] Wei QW. Reproductive behavioral ecology of Chinese sturgeon (Acipenser sinensis Gray) with its stock assessment [Dissertation]. Wuhan: Institute of Hydrobiology, Chinese Academy of Sciences, 2003. [危起伟. 长江中华鲟繁殖行为生态学 与资源评估 [学位论文]. 武汉: 中国科学院水生生物研究所, 2003.]

[42] Zhang SM, Zhang YP, Zheng XZ et al. Molecular phylogenetic systematics of twelve species of acipenseriformes based on mtDNA ND4L -ND4 gene sequence analysis. Science in China: Series C: Life Sciences, 2000, 43(2) : 129-137. DOI: 10. 1007/BF02879121.

[43] Ren H, Lan ZQ, Sun HM et al. Study on the biological characteristics and artificial propagation technology of Acipenser 
dabryanus. Jiangxi Fishery Sciences and Technology, 2014, 139: 19-23. [任华, 蓝泽桥, 孙宏惁等. 达氏鲟生物学特 性及人工繁殖技术研究. 江西水产科技, 2014, 139: 19-23.]

[44] Lu XB, Ni Y, Rao J et al. Resource status and research progress of Acipenser dabryanus. Fisheries Science \& Technology Information, 2012, 39(5): 251-253, 257. [鲁雪报, 倪勇, 饶军等. 达氏鲟的资源现状及研究进展. 水产科技情报, $2012,39(5): 251-253,257$.

[45] Mobile Monitoring Station of Aquatic Animals, the Monitoring System of Ecological Environment of the Three Gorges Project, Institute of Hydrobiology, Chinese Academy of Sciences ed. Annual report of monitoring in 1996, 1997. [中国科学 院水生生物研究所三峡工程生态环境监测系统水生动物流动监测站. 1996 年监测工作年度报告, 1997.]

[46] Yangtze River Fisheries Research Institute, Chinese Academy of Fishery Sciences ed. Annual report of monitoring fish resources and ecological environments in the national nature reserve of rare and endemic fishes in the upper reach of the Yangtze River, 2011. [中国水产科学院长江水产研究所. 长江上游珍稀特有鱼类国家级自然保护区鱼类资源与生态 环境监测 2006 2010 年工作报告, 2011.]

[47] Blakiston TW ed. Translated by Ma J, Sun L. Five months on the Yanq-Tze. Beijing: China Map Press, 2013. [布莱基斯 顿 TW. 马剑, 孙琳译. 江行五月. 北京: 中国地图出版社, 2013.]

[48] Chen YY ed. The fishes of the Hengduan Mountains Region. Beijing: Science Press, 1998. [陈宜瑜. 横断山区鱼类. 北 京: 科学出版社, 1998.]

[49] Liu CH. Some information on Chinese paddlefish. Fisheries Sicence \& Technology Information, 1979, 6(1) : 13-14, 32. [刘成汉. 有关白鲟的一些资料. 水产科技情报, 1979, 6(1): 13-14, 32.]

[50] Deng ZL, Yu ZT, Zhao Y et al eds. Evaluation of the impact of the Three Gorges on Psephurus gladius and Myxocyprinus asiaticus in the Yangtze River and the study of their resources protection//Collected papers on studies on the ecological and environmental impacts of the Three Gorges Project at the Yantze River and their countermeasures. Beijing: Science Press, 1987: 42-52. [邓中粦, 余志棠, 赵燕等. 三峡水利枢纽对长江白鲟和胭脂鱼影响的评价及资源保护研究//长江三 峡工程对生态与环境影响及其对策研究论文集. 北京: 科学出版社, 1987: 42-52.]

[51] Zhang H, Jaric I, Roberts DL et al. Extinction of one of the world's largest freshwater fishes: lessons for conserving the endangered Yangtze fauna. Sci Total Environ, 2020, 710 (in press).

[52] Changshou Lake Fishery Research Institute, Chongqing City, Sichuan Province ed. Preliminary report on the spawning of sturgeon in Jinsha River, 1964. [四川省重庆市长寿湖渔场水产研究所. 金沙江鲟鱼产卵调查初步报告, 1964.]

[53] The Changjiang Aquatic Resources Survey Grouo, Sichuan Province ed. Preliminary observations on the incubation test and the developments of embryo and larvae of sturgeon in Jinsha River, 1973. [四川省长江水产资源调查组. 金沙江鲟鱼的 催青试验及胚胎和仔鱼发育的初步观察, 1973.]

[54] Pratt AE ed. To the snows of Tibet through China. London: Longmans, Green, and Co., 1892.

[55] Liu JK, Cao WX. Fish resources of the Yangtze River basin and the tactics for their conservation. Resources and Environment in the Yangtze Basin, 1992, 1(1): 17-23. [刘建康, 曹文宣. 长江流域的鱼类资源及其保护对策. 长江流域资 源与环境, 1992, 1(1): 17-23.]

[56] Xie P. Biodiversity crisis in the Yangtze River: The culprit was dams, followed by overfishing. J Lake Sci, 2017, 29(6) : 1279-1299. DOI: 10.18307/2017.0601. [谢平. 长江的生物多样性危机一一水利工程是祸首, 酷渔乱捕是帮凶. 湖 泊科学, $2017,29(6): 1279-1299$.]

[57] Xie P ed. Biodiversity crisis in the Yangtze River from point views of evolution and ecology. Beijing: Science Press, 2018. [谢平. 从历史起源和现代生态透视长江的生物多样性危机. 北京: 科学出版社, 2018.] 